\title{
Title: Forests affected by frequent and intense typhoons challenge the intermediate disturbance hypothesis
}

Lixin Wang

Department of Earth Sciences, Indiana University-Purdue University Indianapolis, Indianapolis, IN, 46202, USA

Teng-Chiu Lin ${ }^{1}$

Department of Life Science, National Taiwan Normal University, Taipei, 11677, Taiwan

${ }^{1}$ Corresponding author: tclin@ntnu.edu.tw

\begin{abstract}
Tropical cyclones (hurricanes and typhoons) are extreme disturbances that have a significant impact on ecosystem structure and processes. The intermediate disturbance hypothesis (IDH) generalizes disturbance-diversity relationships but its validity is hotly debated. The IDH has been challenged both theoretically and with results from experimental studies, however, few studies have empirically tested the proposed mechanisms of IDH using results from the actual ecosystems. In this commentary, based on empirical observations from studies on the interactions between tropical cyclones and forest dynamics, we outlined seven possible outcomes of gap dynamics and tree diversity as a result of different frequency and intensity combinations. We argue that the lack of distinction and differentiation between disturbance intensity and severity, and the overlooked role of tree mortality, seedling recruitment, and tree adaptations limit the applicability of IDH in predicting the disturbance-diversity relationship. In the era of climate change characterized with more frequent climate
\end{abstract}


extremes and natural disturbances, we should move beyond the generalizations and directly address the processes leading to the observed disturbance-diversity relationships to make reliable predictions.

\section{KEYWORDS}

frequency; intensity; severity; typhoon 


\section{1 | INTRODUCTION}

Disturbances play an important role in ecosystem structure, function, and dynamics. Large disturbances can reset community development and initiate secondary succession, while in the absence of disturbance a community will eventually reach mature ecosystem state (Whittaker, 1953, 1974; Horn, 1974). A key discussion in ecosystem ecology is the relationship between disturbance and diversity. Disturbances have the potential to alter species diversity directly through differential species removal and indirectly through modifying the biotic and abiotic environments and thereby altering the species competition (Glitzenstein, Harcombe, \& Streng, 1986; Hughes et al., 2007). Many theories and hypotheses have been developed to describe and predict the relationship between disturbance and species diversity. Among them, the intermediate disturbance hypothesis (IDH) (Connell, 1978; Ward and Stanford, 1983) is fundamental in explaining and predicting disturbance-diversity relationships. The IDH has been debated over the past decades with no clear consensus on how well it can be applied to the actual ecosystems. In this commentary, we used results from empirical studies of tropical cyclone disturbance on forest ecosystems to illustrate several key limitations of the IDH and reveal previously overlooked processes that are essential to the disturbance-diversity relationship.

\section{2 | RETHINKING THE INTERMEDIATE DISTURBANCE HYPOTHESIS}

The IDH predicts that local species diversity (i.e., richness) peaks at intermediate frequencies and spatial extents of disturbance (Connell, 1978). The mechanisms that lead to the peak local diversity at intermediate disturbance is that at low disturbance (both in terms of frequency and intensity), the community is disproportionally made up of species that are best adapted to the prevailing environmental conditions, and when disturbance is too large, 
many species are removed by the disturbance (Petraitis, Latham, \& Niesenbaum, 1989;

Wilson \& Tilman, 2002; Catford et al., 2012). The IDH has been both supported (Mollino and Sabatier, 2001, Roxburgh, Shea, \& Wilson; 2004, Bongers et al., 2009, Zimmerman et al. 2014) and challenged (Hubbell et al., 1999; Miller, Roxburgh, \& Shea, 2011; Fox 2013) by large numbers of studies, with the latter mostly using laboratory experiments or theoretical studies. As a support to IDH, using a sample of 17,000 trees in a Guianan forest, with a wide range of disturbance intensities, Molino and Sabatier (2001) reported peaked species richness at intermediate disturbance levels. Using another large-scale dataset, Bongers et al. (2009) illustrated that richness peaks at intermediate disturbance in tropical dry forests. At the same time, there are many studies challenging the IDH. Fox (2013) argued that the IDH is empirically refuted by the lack of humped shape of diversity along the disturbance gradient in many cases and the mechanisms that contribute to high levels of diversity at intermediate disturbance are logically invalid. Using a model of two competing plant species subject to disturbance of varying intensities and frequencies, Miller, Roxburgh, \& Shea (2011) demonstrated that a single simple model can theoretically generate several different disturbance-diversity relationships. However, it has been argued that many criticism about the IDH are misguided because they fail to acknowledge that the effects of disturbance on diversity co-vary with productivity (Huston, 2014).

Although the mechanisms provided by the IDH have been challenged both theoretically and experimentally, to our knowledge, few studies have empirically tested the theoretical mechanisms of the IDH using results from actual ecosystems. Based on empirical results of studies on plant species diversity in relation to tropical cyclone disturbance, we examined the two fundamental mechanisms of the IDH, maximized competitive exclusion under low disturbance and maximized species loss under high disturbance. We also highlight key 
processes driving the disturbance-diversity relationship that have not been explicitly addressed previously.

Tropical cyclones are among the most-common natural disturbances globally and their frequency and intensity are projected to increase in many parts of the world in the future (Emanuel 2005, 2013; Chand, Tory, Ye, \& Walsh, 2017; Ibanez et al., 2018). In fact, tropical cyclone disturbance was used many times to illustrate the IDH by Connell (1978). The IDH predicts a low level local species richness under high disturbance, however, empirical studies from Taiwan, an island under frequent and intense typhoon disturbances do not support such a prediction. Taiwan experiences three to six landfall typhoons annually, with approximately $40 \%$ of the typhoons category 3 (Saffir-Simpson scale, wind speed $50-58 \mathrm{~m} \mathrm{~s}^{-}$ ${ }^{1}$ ) or greater (Lin et al., 2011). Thus, typhoon disturbance in Taiwan is at the very high end of the cyclone disturbance spectrum. Northeastern Taiwan had a record of six typhoons in 1994, with two of them category 3 at landfall. However, tree mortality caused by the 1994 typhoons was only $1.4 \%$ and there was no differential removal of tree species at a low elevation forest (Mabry et al., 1998). When mortality is low and not many species are preferentially removed, frequent cyclone disturbance may help to maintain or even enhance tree diversity (Lin et al., 2018). Sometimes higher local species richness can indeed result from high disturbance intensity. For example, in the Caribbean basin of central America where major hurricanes occur once or twice a decade (Walker, Lodge, Brokaw, \& Waide, 1991), Vandermeer et al. (2000) reported that after the category 4 (wind speed 58-70 $\mathrm{m} \mathrm{s}^{-1}$ ) Hurricane Joan (1988) affected Nicaragua, species richness was higher in disturbed forests than undisturbed forests. These observations clearly demonstrate that intensive disturbance that affects an extensive area does not always lead to lower diversity as predicted by the IDH. We argue that seed recruitment under cyclone disturbance disrupts the disturbance- 
diversity relationship predicted by the IDH. The pioneer species rely on large seed reserves in the seed bank to achieve abundance after cyclone disturbance. However, with extensive disturbance of high intensity, seed recruitment of pioneer species will not be sufficient to saturate the damaged area so that they can not suppress the large suite of slower-growing species as they often do under less intensive disturbances (Vandermeer et al., 2000).

Another important limitation of the IDH is the lack of distinction between the effects of disturbance frequency and intensity on species diversity. Connell (1978) proposed that the same reasoning used to explain the disturbance frequency-diversity relationship can be applied to explain disturbance intensity (and area)-diversity relationship. However, it is widely recognized in fire ecology that frequent fires are typically less intense and have smaller spatial coverage while infrequent fires are usually intense and cover much broader areas and their effects on plant diversity are likely different (Pickett and White, 1985, Turner et al., 1989; Steel, Safford, \& Viers, 2015). Similar to fires, the effects of different tropical cyclone disturbance regimes (e.g., frequent and intense, frequent but less intense, and rare but intense) on tree diversity are also different.

Another limitation of IDH in explaining disturbance-diversity relationship is the lack of consideration of organismal adaptations to disturbance. According to the IDH, tree diversity is low under frequent and intense cyclone disturbance regime. Lin et al. (2017) used empirical evidence to illustrate that strong typhoons do not lead to low levels of local species diversity because of low tree mortality. The low tree mortality even during most intense typhoons is likely resulted from the development of adaptations to frequent typhoon disturbance. Natural disturbances have been interacting with ecosystems for hundreds of thousands of years and spanning over many generations of trees in many regions. It is therefore not surprising that selection had resulted in forests with structure, 
composition, and functional traits that are adaptive to cyclone disturbance such as short stature and heavy defoliation that would minimize their mortality (Francis and Alemany, 2003; Lin et al. 2017). Adaptations also likely contributed to the finding that cyclonic storms generally have a greater effect on forest composition and dynamics on forests with less frequent cyclone disturbance than on those with more frequent disturbance reported by Hogan et al. (2018). We believe that the overlooked role of adaptations by the IDH is one reason for the lack of humped-shape disturbance-diversity relationship in many cases.

Lastly, we believe that there is an important distinction between disturbance intensity and disturbance severity, and one cannot be interchanged with the other. Intensity is a physical attribute of disturbance (e.g., the strength of the disturbing force) and severity is the biophysical impact, such as the magnitude of tree mortality caused by disturbance (Iwasaki and Noda, 2018). When testing the IDH, some researchers have confused disturbance severity with disturbance intensity, which is subjected to criticism. For example, Molino and Sabatier (2001) provided a testing of the IDH at the light-gap level, in which they used tree mortality to estimate disturbance level. In the criticism to the IDH, Huston (2014) sometimes also used mortality in substitution of disturbance intensity to describe possible outcomes of the disturbance-diversity relationship. It is problematic to use disturbance severity instead of disturbance intensity to define the scale of the disturbance. For example, it is inappropriate to classify the category 3 Typhoon Herb as a small disturbance just because it caused less than $1 \%$ tree mortality (Lin et al., 2011). Such confusion is especially problematic in forest management aiming to mitigate the disturbance effects. For example, through thinning it is possible to reduce tree mortality caused by a category 3 tropical cyclone but it would be misleading to then use the low tree mortality to claim that the tropical cyclone is a small one. 


\section{3 | PROPOSED OUTCOMES OF CYCLONE DISTURBANCE-DIVERSITY RELATIONSHIP}

Based on empirical results, we summarized nine combinations along the frequency and intensity gradients and pointed out seven possible outcomes of cyclone disturbancediversity relationships (Figure 1). When cyclone intensities are low, their effect on tree survival and growth is minor, tree diversity is likely insensitive to cyclone disturbance regardless of the frequency (Figure $1 \mathrm{~A}$ ). In contrast, infrequent but high intensity cyclones could cause high tree mortality. High tree mortality that is not evenly distributed among tree species could reduce tree diversity as predicted by the IDH. In such cases, if the frequency is low, with a return interval of several decades or longer, tree diversity is reduced following the disturbance for one to several decades (Figure 1E). Then canopy tree species removed by the disturbance can regain their niches in the forest as long as there is sufficient supply of seedlings from the seed bank. If the frequency is high, such as in northern Taiwan, species that are vulnerable to the typhoons have too short a period to regain their niches once removed by the disturbance (Figure 1G). Within the same region, there could be a gradient of cyclone intensity under similar cyclone frequency. For example, in Taiwan, where typhoon disturbance occurs on an annual basis, typhoon intensity decreases from low to high elevations, due to the disruption of typhoon structure by the rough topography and cooler temperatures at high elevations. Thus, there is a disturbance intensity gradient under high disturbance frequency (i.e., increasing intensity from scenarios $A, D$, and $G$ ). In the northeastern United States, where hurricanes occur one to several times a century, the decreases in hurricane intensity from coast to inland portray a disturbance intensity gradient under low disturbance frequency (i.e., increasing intensity from scenarios $A, B$, and E). In the Central America, where hurricane occurs once or twice a decade, the decreases in hurricane intensity from east to west coast illustrate a disturbance intensity gradient under 
intermediate disturbance frequency (i.e., increasing intensity from scenarios $A, C$, and F). The effects of cyclone disturbance on tree diversity likely vary along each of the intensity gradients and the lack of distinction between frequency and intensity effects makes the IDH of limited applicability in the actual ecosystems. The seven possible outcomes agree with the theoretical model of Miller, Roxburgh \& Shea (2011) and the experimental populations of microbes used by Hall et al. (2012) that describe changes in disturbance-diversity relationships with different combinations of disturbance frequency and intensity. However, our predicted outcomes are based on results from empirical field studies.

\section{4 | Summary}

Based on empirical field observations from regions under tropical cyclone influences, we have illustrated that some key limitations of the IDH are the lack of distinction between the effects of disturbance frequency and intensity on species diversity, the lack of consideration of organismal adaptations to disturbance, and the lack of distinction between disturbance intensity and disturbance severity. We also showed that intensive disturbance does not always lead to lower diversity and revealed previously overlooked processes (i.e., role of tree mortality and tree adaptations) that are essential to the disturbance-diversity relationship. We have summarized seven possible outcomes of cyclone disturbance-diversity relationships, pointing out the diverse consequences resulting from different disturbance intensity and frequency combinations.

\section{ACKNOWLEDGMENTS}

The authors have no conflict of interest. This study was supported in part by grants from Ministry of Science and Technology, Taiwan (MOST 103-2621-B-003-002-MY3) and by the 
"Innovation and Development Center of Sustainable Agriculture of National Chung Hsing University" from The Featured Areas Research Center Program within the framework of the Higher Education Sprout Project by the Ministry of Education (MOE) in Taiwan. LW acknowledges partial support from Division of Earth Sciences of National Science Foundation (NSF EAR-1562055) and from the Agriculture and Food Research Initiative program (201767013-26191) of the USDA National Institute of Food and Agriculture. We are grateful for the constructive comments from Dr. J. Aaron Hogan and one anonymous reviewer, which significantly enhanced the quality of the manuscript.

\section{REFERENCES}

Bongers, F., Poorter, L., Hawthorne, W. D., \& Sheil, D. (2009). The intermediate disturbance hypothesis applies to tropical forests, but disturbance contributes little to tree diversity. Ecology Letters, 12, 798-805.

Catford, J. A., Daehler, C. C. , Murphy, H. T., Sheppard, A. W., Hardesty, B. D., Westcott, D. A., Rejmánek, M., Bellingham, P. J., Horvitz, C. C., \& Hulme, P. E. (2012). The intermediate disturbance hypothesis and plant invasions: Implications for species richness and management. Perspectives in Plant Ecology, Evolution and Systematics, 14, 231-241.

Chand, S. S., Tory, K. J., Ye, H., \& Walsh, K. J. (2017). Projected increase in El Nino-driven tropical cyclone frequency in the Pacific. Nature Climate Change, 7, 123-127.

Connell, J. H. (1978). Diversity in tropical rain forests and coral reefs. Science, 199, 13021310.

Emanuel, K. (2005). Increasing destructiveness of tropical cyclones over the past 30 years. Nature, 436, 686.

Emanuel, K. A. (2013). Downscaling CMIP5 climate models shows increased tropical cyclone 
activity over the 21st century. Proceedings of the National Academy of Sciences, 110, $12219-12224$.

Fox, J. W. (2013). The intermediate disturbance hypothesis should be abandoned. Trends in Ecology \& Evolution, 28, 86-92.

Francis J. K., \& Alemañy, S. E. (2003). Hurricane damage to mahogany crowns associated with seed Source. In: Lugo A. E., Figueroa Colón, J. C., \& Alayón, M. (eds) Big-Leaf Mahogany. Ecological Studies (Analysis and Synthesis), vol 159. pp. 94-102, Springer, New York, New York, USA.

Glitzenstein, J. S., Harcombe, P. A., \& Streng, D. R. (1986). Disturbance, succession, and maintenance of species diversity in an east Texas forest. Ecological Monographs, 56, 243-258.

Hall, A. R., Miller, A. D., Leggett, H. C., Roxburgh, S. H., Buckling, A., \& Shea, K. 2012. Diversity-disturbance relationships: frequency and intensity interact. Biology Letters, rsbl20120282.

Hogan J, Zimmerman, J., Thompson, J., Uriarte, M., Swenson, N., Condit, R., Hubbell, S., Johnson, D., Sun, I., Chang-Yang, C. H., \& Su, S. H. (2018). The frequency of cyclonic wind storms shapes tropical forest dynamism and functional trait dispersion. Forests, $9,404$.

Horn, H. S. (1974). The ecology of secondary succession. Annual Review of Ecology and Systematics, 5, 25-37.

Hubbell, S. P., Foster, R. B., O'Brien, S. T., Harms, K. E., Condit, R., Wechsler, B., Wright, S. J., Loo, S., \& de Lao, S. L. (1999). Light-gap disturbances, recruitment limitation, and tree diversity in a neotropical forest. Science, 283, 554-557.

Hughes, A. R., Byrnes, J. E., Kimbro, D. L., \& Stachowicz, J. J. (2007). Reciprocal relationships 
and potential feedbacks between biodiversity and disturbance. Ecology Letters, 10, 849-864.

Huston, M. A. (2014). Disturbance, productivity, and species diversity: empiricism vs. logic in ecological theory. Ecology, 95, 2382-2396.

Ibanez, T., Keppel, G., Menkes, C., Gillespie, T. W., Lengaigne, M., Mangeas, M., Rivas-Torres, G., \& Birnbaum, P. (2019). Globally consistent impact of tropical cyclones on the structure of tropical and subtropical forests. Journal of Ecology, 107, 279-292.

Iwasaki, A., \& Noda, T. (2018). A framework for quantifying the relationship between intensity and severity of impact of disturbance across types of events and species. Scientific Reports, 8, 795.

Lin, S. Y., Shaner, P. J. L., \& Lin, T. C. (2018). Characteristics of old-growth and secondary forests in relation to age and typhoon disturbance. Ecosystems, 21, 1521-1532.

Lin, T. C., Wang, L., Zheng, C., McEwan, R., Chang, C. T., Chiang, J. M., \& Chi, C. H. (2017). Tropical cyclones disrupt the relationship between tree height and species diversity: Comment. Ecosphere, 8, e01938.

Lin, T. C., Hamburg, S. P., Lin, K. C., Wang, L. J., Chang, C. T., Hsia, Y. J., Vadevoncoeur, M. A., McMullen, C. M. M., \& Liu, C. P. (2011). Typhoon disturbance and forest dynamics: lessons from a Northwest Pacific subtropical forest. Ecosystems, 14, 127-143.

Mabry, C. M., Hamburg, S. P. , Lin, T. C., Horng, F. W., King, H. B., \& Hsia, Y. J. (1998). Typhoon disturbance and stand-level damage patterns at a subtropical forest in Taiwan. Biotropica, 30, 238-50.

Miller, A. D., Roxburgh, S. H., \& Shea, K. (2011). How frequency and intensity shape diversity-disturbance relationships. Proceedings of the National Academy of Sciences, $108,5643-5648$. 
Molino, J. F., \& Sabatier, D. (2001). Tree diversity in tropical rain forests: a validation of the intermediate disturbance hypothesis. Science, 294, 1702-1704.

Petraitis, P. S., Latham, R. E., \& Niesenbaum, R. A. (1989). The maintenance of species diversity by disturbance. The Quarterly Review of Biology, 64, 393-418.

Pickett, S. T. A., \& White, P. S. (1985). The ecology of natural disturbance and patch dynamics. Academic Press, Orlando, Florida, USA.

Roxburgh, S. H., Shea, K., \& Wilson, J. B. (2004). The intermediate disturbance hypothesis: patch dynamics and mechanisms of species coexistence. Ecology, 85, 359-371.

Steel, Z. L., Safford, H. D., \& Viers, J. H. (2015). The fire frequency-severity relationship and the legacy of fire suppression in California forests. Ecosphere, 6, 1-23.

Turner, M. G.,. Gardner, R. H , Dale, V. H., \& O'Neill, R. V. (1989). Predicting the spread of disturbance across heterogeneous landscapes. Oikos, 55, 121-129.

Vandermeer, J., de la Cerda, I. G., Boucher, D., Perfecto, I., \& Ruiz, J. (2000). Hurricane disturbance and tropical tree species diversity. Science, 290, 788-791.

Walker, L. R., Lodge, D. J., Brokaw, N. V. L., \& Waide, R. B. (1991). An introduction to Hurricanes in the Caribbean. Biotropica, 23, 313-316.

Ward, J. W., \& Stanford, J. A. (1983) Intermediate-disturbance hypothesis: an explanation for biotic diversity patterns in lotic ecosystems. Dynamics of Lotic Systems, Ann Arbor Science, Ann Arbor Michigan, USA.

Whittaker, R. H. (1953). A consideration of climax theory: the climax as population and pattern. Ecological Monographs, 23, 41-78.

Whittaker, R. H. (1974). Climax concepts and recognition. In Knapp R. (ed.) Vegetation dynamics . Handbook of Vegtation Science 8. Junk, the Hague, pp. 137-154, Springer, Dordrecht, Germany. 
Wilson, S. D., \& Tilman, D. (2002). Quadratic variation in old-field species richness along gradients of disturbance and nitrogen. Ecology, 83, 492-504.

Zimmerman, J. K., Hogan, J. A., Shiels, A. B., Bithorn, J. E., Carmona, S. M., \& Brokaw, N.

(2014). Seven-year responses of trees to experimental hurricane effects in a tropical rainforest, Puerto Rico. Forest Ecology and Management, 332, 64-74. 


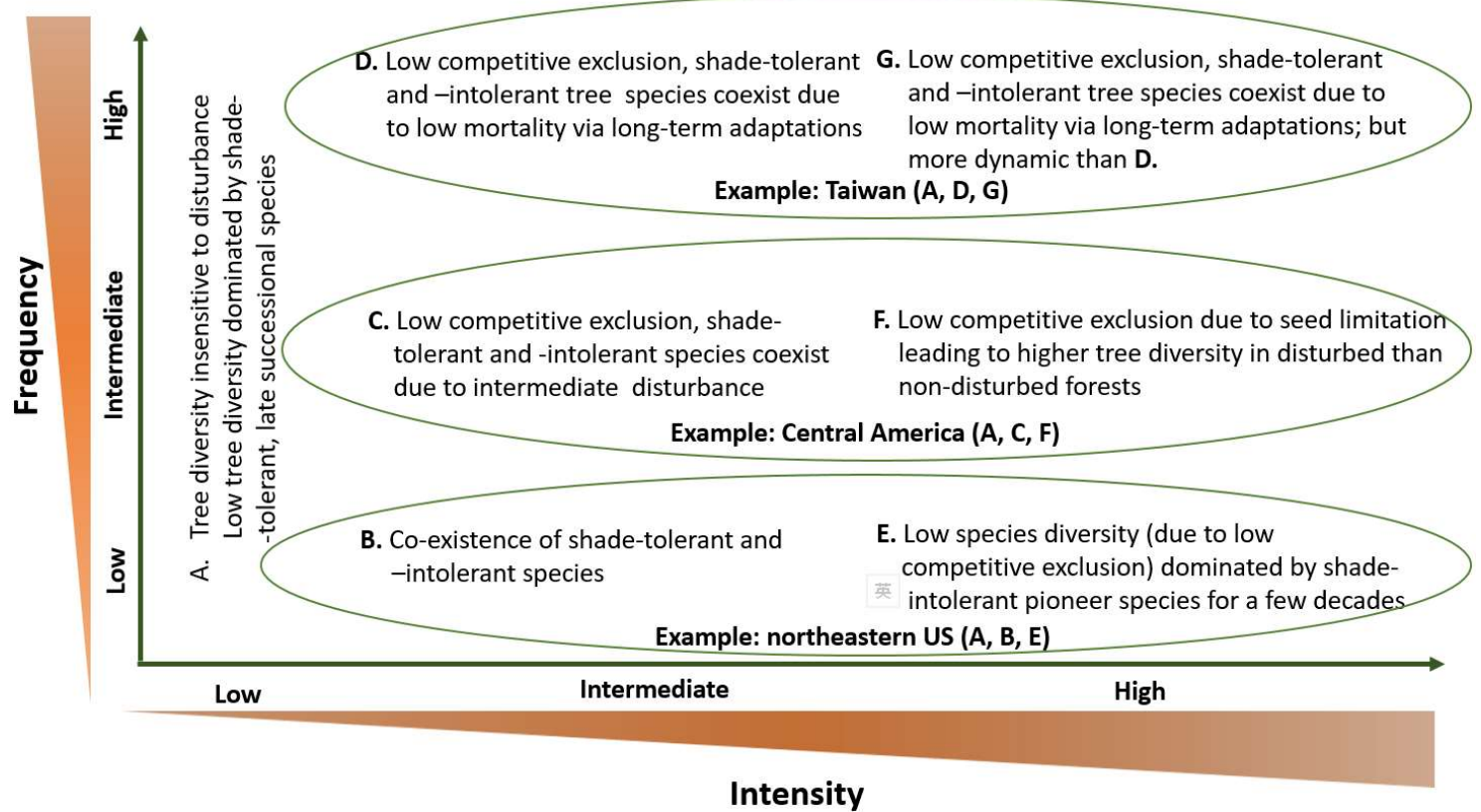

Figure 1. Seven possible outcomes of gap dynamics and tree diversity in relation to disturbance as a result of different frequency and intensity combinations. In places such as Taiwan where typhoon disturbance is on an annual basis, the decreases in typhoon intensity from low to high elevations, due to the destruction of typhoon structure by the rough topography and cooler temperatures at high elevations, represent a gradient of increasing disturbance intensity (i.e., scenarios $A, D$, and G) under high disturbance frequency. In the Central America, where hurricanes occur once or twice a decade, the decreases in hurricane from east coast to west coast illustrate a gradient of intermediate disturbance frequency but increasing disturbance intensity (i.e., scenarios A, C, and F). The scenario C represents the co-existence of shade-tolerant and -intolerant species under intermediate intensity and intermediate frequency due to low competitive exclusion as predicted by the intermediate disturbance hypothesis. Their co-existence, however, is not limited to scenario $\mathrm{C}$ but also in other scenarios (e.g., D, G) due to different reasons. In the northeastern United States, where hurricanes occur one to several times a century, the decreases in hurricane intensity from coast to inland portray a gradient of increasing disturbance intensity under low disturbance frequency (i.e., scenarios $A, B$ and $E$ ). 